\title{
Inequity in the provision of and access to palliative care for cancer patients. Results from the Italian survey of the dying of cancer (ISDOC)
}

\author{
Monica Beccaro* ${ }^{\star 1}$, Massimo Costantini ${ }^{\dagger 1}$, Domenico Franco Merlo ${ }^{\dagger 2}$ and \\ the ISDOC Study Group
}

\author{
Address: ${ }^{1}$ Unit of Clinical Epidemiology, National Cancer Institute, Genova, Italy and ${ }^{2}$ Unit of Epidemiology and Biostatistics, National Cancer \\ Institute, Genova, Italy \\ Email: Monica Beccaro* - monica.beccaro@istge.it; Massimo Costantini - massimo.costantini@istge.it; \\ Domenico Franco Merlo - franco.merlo@istge.it \\ * Corresponding author †Equal contributors
}

Published: 27 April 2007

BMC Public Health 2007, 7:66 doi:10.1 I86/147/-2458-7-66

This article is available from: http://www.biomedcentral.com/I47/-2458/7/66

(c) 2007 Beccaro et al; licensee BioMed Central Ltd.

This is an Open Access article distributed under the terms of the Creative Commons Attribution License (http://creativecommons.org/licenses/by/2.0), which permits unrestricted use, distribution, and reproduction in any medium, provided the original work is properly cited.

\begin{abstract}
Background: The palliative services and programs have been developed with different intensity and modalities in all countries. Several studies have reported that a geographic variation in the availability and provision of palliative care services between and within countries exists, and that a number of vulnerable groups are excluded from these services. This survey estimates the distribution of places of care for Italian cancer patients during the last three months of their lives, the proportion receiving palliative care support at home and in hospital, and the factors associated with the referral to palliative care services.
\end{abstract}

Methods: This is a mortality follow-back survey of 2,000 cancer deaths identified with a 2-stage probability sample, representative of the whole country. Information on patients' experience was gathered from the non-professional caregiver through an interview, using an adapted version of the VOICES questionnaire. A section of the interview concerned the places of care and the palliative care services provided to patients. Multivariate logistic regression analyses were conducted to identify the determinants of palliative care service use.

Results: Valid interviews were obtained for $67 \%$ of the identified caregivers $(n=1,271)$. Most Italian cancer patients were cared for at home $(91 \%)$ or in hospital $(63 \%)$, but with substantial differences within the country. Only I4\% of Italian cancer patients cared for at home against $20 \%$ of those admitted to hospital, received palliative care support. The principal determinants identified for receiving these service were: an extended interval between diagnosis and death $(P=0.0 I)$ and the caregiver's high educational level $(P=0.0 \mathrm{I})$ for patients at home; the low patient's age $(P<0.0 \mathrm{I})$ and the caregiver's high educational level $(P=0.01)$ for patients in hospital.

Conclusion: In Italy palliative care services are not equally available across the country. Moreover, access to the palliative care services is strongly associated with socio demographic characteristics of the patients and their caregivers. Italian Policy-makers need to equalise palliative care provision and access across the country to meet the needs of all cancer patients. 


\section{Background}

The provision of palliative care services and programs for terminal ill patients has become an important public health issue during recent decades. The worldwide development of hospices and the growing number of hospital and domiciliary palliative care teams (PCTs) differ between countries, reflecting the heterogeneity of the health care systems, patient's needs, and cultures [1-3]. Recent studies show that a remarkable geographic variation exists in the availability and provision of hospice and other palliative care services [4-6] also within the countries. Two literature reviews show that access and referral to specialist palliative care services are unequally distributed among cancer patients [4,7]. Cancer patients are less likely to receive palliative care if they are elderly, have no informal carer support, a low socio-economic status, poor functioning and a high nursing care requirement, a short term survival and a diagnosis of haematological, gastrointestinal, or central nervous system (CNS) tumours [4,7$14]$.

In all Western countries a very high proportion of terminally ill cancer patients are cared for and die in acute care hospitals where often PCTs are lacking [15-19]. As far as we know, previous studies have not identified the factors associated with the utilization of hospital-based palliative care support.

Published research on this topic, is based on geographically restricted populations that are often limited to specific palliative care programs existing in that region. [4,714,20] No population-based study, estimating at a national level, the spatial distribution, availability and accessibility of palliative care services for all cancer patients is available.

The Italian Survey of the Dying Of Cancer (ISDOC) is a mortality follow-back survey conducted in a stratified random sample of Italian deceased from cancer between March 2002 and June 2003. Information regarding the advanced and terminal phase of cancer was obtained from the caregivers, interviewed after the patient's death by using the View of Informal Carers - Evaluation of Services (VOICES) questionnaire [21].

ISDOC's aim is to use the information gathered during the interviews to provide national estimates of the end of life care experiences of terminal cancer patients in Italy.

This paper reports the results from specific sections of the interview focused on the places of care and the palliative care services provided to cancer patients during the last three months of life. Specifically, the analysis is aimed at:
- describing the places of care (home, hospital, nursing home and hospice) of cancer patients in Italy during the last three months of life;

- evaluating the validity of information concerning the referral for domiciliary PCTs, as reported by the caregivers during the interviews;

- estimating the proportion of Italian cancer patients who received palliative care support at home or in hospital;

- analyzing the socio-demographic factors associated with the referral of cancer patients in Italy for domiciliary PCTs, for hospital PCTs or pain specialists during hospital admissions.

\section{Methods \\ The Italian Survey of the Dying Of Cancer (ISDOC)}

A 2-stage probability sample was used to estimate end-oflife outcomes of approximately 160,000 annual cancer deaths in Italy. In the $1^{\text {st }}$ sampling stage, 30 out of 197 existing Local Health Districts (LHD) were randomly selected, following stratification by four Italian geographical areas. In the $2^{\text {nd }}$ stage, a fixed proportion of adult cancer deaths (aged 18 years or more) were drawn from each LHD, contributing to a sample of 2,000 death certificates of deceased for cancer between March 2002 and June 2003 [21].

For each case included in the survey, the non-professional caregiver, who was defined as the closest and the best informed person about the patient's last three months of life, was identified. A letter was sent to all identified caregivers to inform them of the study aims and obtain formal consent to be interviewed. Three to 10 days later, a trained interviewer contacted the identified caregiver to discuss the interview in detail. Information regarding the methodology of the survey has been published in a previous article [21].

The non-professional caregiver was identified for $92.1 \%$ of deceased patients $(n=1,843)$. For 57 cases, with no recognized non-professional support $(2.9 \%)$, the professional caregiver was identified.

An interview was conducted with 1,289 (67.8\%) of the 1,900 identified caregivers at an average of 234 days after the patients' death (range 103-374). Of the remaining 611 non-interviewed caregivers, $161(8.5 \%)$ could not be located, $383(20.1 \%)$ refused to be interviewed, 38 $(2.0 \%)$ were too ill to participate, and $7(0.4 \%)$ were deceased. Twenty-two interviews $(1.1 \%)$ were not carried out due to staff errors during planning. Finally excluded from all the statistical analyses were: 6 patients, whose death was thought not to be due to cancer, 12 who did not 
reach the terminal phase of disease (they died during the diagnostic phase, active treatments or diagnosis was postmortem) [21]. The study design was approved by the Ethical Committee of National Cancer Institute of Genoa, and, according to the Italian law on use and processing of health data, a notification of the study design and procedures was sent to the Italian Data Protection Commission.

\section{Data collection}

The interviewer met the caregiver, usually in his/her home, where she/he conducted a semi-structured interview using an adapted version of the VOICES questionnaire [22]. A specific section of the interview concerned information regarding care settings and the palliative care services delivered to the cancer patients. The questions asked to the caregiver are reported below.

During the last three months of life, did the patient spend any time at home, in a nursing home, in hospital or in a hospice?

$>$ Home: While the patient was at home, was she/he referred for domiciliary PCTs? If YES, please specify the date of the first home visit.

Hospital: While the patient was in hospital, was a pain specialist involved in her/his care?

The information regarding admission to hospital in the last three months of life concerned:

- If the patients died in hospital, the last admission to hospital (for the admissions > 24 hours);

- If the patients died elsewhere, the longer admission to hospital.

\section{Validity of the information collected during the interview} regarding domiciliary $P C T$ s

To verify the validity of the information reported by the caregivers during the interview concerning the referral of the patients for domiciliary PCTs, we contacted, at the end of the study, all domiciliary PCTs active in the Local Health Districts (LHD) sampled for this study. The identified sample of cancer deaths was cross-checked with the database of domiciliary PCTs, in order to obtain a valid list of patients who were followed or not, by the domiciliary PCTs (and the date of the first home visit).

All statistical analyses were based on socio demographic characteristics of patients and their caregiver collected during the interviews. The referral of patients for PCTs during the time they spent at home was obtained from the case sheets. The domiciliary PCTs case sheets, containing comprehensive and detailed information regarding the referral and the date of the first home visit has been considered to be the "gold standard",

\section{Statistical methods}

All analyses were performed using SUDAAN version 9.0.1 (Research triangle Institute, Research Triangle Park, NC). This software, for the point and SE statistics estimation, takes into account four characteristics of complex survey data: the unequal probability selection of observations, the clustering of observations, stratification, and nonresponse. Sampling weights were introduced to obtain unbiased weighted point and standard errors (SE) estimates of the target population. Specifically, weights were introduced to adjust for the different probability to be selected in each of the four strata (the LHD were sampled disproportionately in each stratum), and to adjust for the different proportion of valid information obtained in each of the 30 LHD selected. The number of cancer deaths in different subgroups, have been estimated, using 1998 mortality data.

The level of agreement between information reported by the caregiver during the interview and data collected from the domiciliary PCTs case sheets, was examined using kappa statistics. Moreover, sensitivity and specificity of the information collected during the interviews were evaluated assuming that the information reported in the case sheets was the "gold standard".

The differences in the distribution of categorical variables (i.e., gender and marital status, place of residence, primary tumor, and caregiver relationship) were tested by means of chi-square test for heterogeneity. For ordinal variables, such as age at death, education, months since diagnosis, number of cohabitants, age, and education of the caregivers, the differences in their distribution were tested by means of chi-square test for trend.

Two multivariate logistic regression models were performed to examine the associations between patients' and caregivers' characteristics (the independent variables) and the referral of patients for PCTs at home (first model) and to a pain specialist during hospital admission (second model). Patients' and caregivers' characteristics (i.e. age at death, gender, education, marital status, place of residence, primary tumour, months since diagnosis and number of cohabitants for patients, and caregiver's relationship, age, gender and education) were all included in the logistic regression models. Variables with $\mathrm{P}>0.10$ were removed from each model by means of a step-down procedure to obtain the final models. For the variables included in the final logistic models, the strength of the association was estimated in terms of odds ratio (OR), the 
ratio of the odds to be referred to PCTs at home (first model) or to a pain specialist (second model) among patients in a given category to the corresponding odds in a reference category. In each model, the chi-square test statistics for heterogeneity and for trend were used to test the associations between the dependent variable and the independent categorical and ordinal variables, respectively.

To compare the availability of the domiciliary and hospice PCTs in the 30 LHD examined in the ISDOC study in 2002-2003, with current availability (1 ${ }^{\text {st }}$ June 2006 ) all local palliative care referents were contacted and the Italian Society of Palliative Care (SICP) [23] database consulted.

\section{Results \\ Places of care (Table I)}

The estimated proportion of Italian cancer patients who spent all or part of the last three months of life at home was $90.8 \%$ (95\% CI: 88.0 - 93.0). 63.4\% (95\% CI: 59.0 67.7) of the patients were admitted to hospital during this period. A small but non-negligible proportion of patients (8.3\%; 95\% CI: 6.2 - 11.0) spent this time in a nursing home and only $0.7 \%$ (95\% CI: $0.3-1.8)$ in a hospice.

The highest proportion of patients cared for at home was in the Southern regions of Italy $(97.8 \%)$ as compared to the other regions. Conversely, patients were more frequently admitted to hospital in the Northern regions (73.5\% in the North East and 66.4\% in the North West) as compared to Southern regions (51.2\%). The admission to nursing homes was negligible in the South $(0.9 \%)$ compared to the Central and Northern regions (from $6.5 \%$ in Central Italy to $13.5 \%$ in the North East).

About one third (31.3\%) of patients spent the whole of the last period of their life at home, $4.5 \%$ in nursing homes, and $2.9 \%$ in hospital. The most frequently reported combination was home and hospital, that accounted for $56.9 \%$ of the sample. Statistically significant differences among the 4 geographical areas $(\mathrm{P}<$ 0.001) were observed. Particularly striking was the proportion of patients cared for at home for the whole period in the South of Italy (47.9\%), as compared to the others geographical areas, where the proportion of home cared for ranged between $17.0 \%$ in the North East and $32.3 \%$ in the Central regions.

\section{Validity of information collected during the interviews about domiciliary palliative care teams (Table 2)}

Agreement between the two sources of information (those reported in the case sheets and those collected during the interview with the caregivers) about the referral for domiciliary PCTs was high (kappa $=0.86)$. The overall preva- lence of referral from the two sources was similar (16.5\% and $17.0 \%$, respectively), and the misclassification rate minimal. Assuming the domiciliary PCTs case sheets as "gold standard", the sensitivity and specificity of the interviews with the caregivers as a source of this information was 89.8\% (95\% CI 85-94) and 97.3\% (95\% CI 96-98), respectively.

Information regarding the date of referral of $183 / 186$ (98.4\%) patients was collected through the case sheets. The average time in care was 100.2 days $(\mathrm{SD}=223.6)$ (median 46). Conversely, information regarding the date of referral of $126 / 167(75.5 \%)$ patients was collected through the caregivers' interview. According to the caregivers, the average time in care was 92.3 days $(\mathrm{SD}=$ 136.5) (median 56).

The proportion of patients who died within 7 days of referral was $9.3 \%$ in the case sheets and $9.5 \%$ reported by the caregivers. The proportions of patients that lived longer than 180 days was $9.3 \%$ (case sheets) and $10.3 \%$ (caregivers).

\section{Referral to domiciliary PCTs (Table 3)}

Overall, the estimated proportion of Italian cancer patient referred for domiciliary PCTs was $13.5 \%$ (95\% CI: $8.1-$ 21.5). These patients were less frequently elderly (patients aged 85 years or more were $5.8 \%$ ), single $(9.8 \%)$, and lived in the South of Italy $(2.3 \%)$. The proportion of patients with haematological tumours referred to domiciliary PCTs was very low (5.9\%) compared to all other type of tumours. An increasing linear trend was observed with the period since diagnosis $(\mathrm{P}<0.01)$, the caregiver's educational level $(P=0.02)$, and, although with a $P=0.08$, with the patient's educational level. Patients with a spouse-partner or child as a caregiver had a greater likelihood to be referred for domiciliary PCTs $(P=0.03)$. There were no significant differences in the referral for domiciliary PCTs by patient's gender $(\mathrm{P}=0.66)$, number of cohabitants $(P=0.69)$, caregiver 's gender $(P=0.13)$ or age $(P=0.85)$.

\section{Involvement of a pain specialist during hospital admissions (Table 4)}

Overall, the estimated proportion of Italian cancer patient followed by a pain specialist during hospital admissions was $19.6 \%$ (95\% CI 15.5-24.5).

A decreasing linear trend was observed with patient's age $(\mathrm{P}<0.01)$ and a positive association with patient's and caregiver's educational level $(\mathrm{P}=0.01$ and $\mathrm{P}<0.01$, respectively). There were no significant differences by patient's gender $(P=0.74)$, marital status $(P=0.72)$, place of residence $(P=0.12)$, type of tumour $(P=0.54)$, months since diagnosis $(\mathrm{P}=0.21)$, number of cohabitants $(\mathrm{P}=$ 
Table I: places of care of Italian cancer patients in the last three months of life.

\begin{tabular}{|c|c|c|c|c|c|}
\hline & North West & North East & Center & South & Italy \\
\hline Survey sample & 604 & 209 & 241 & 217 & $|, 27|$ \\
\hline Italian cancer deaths ${ }^{3}$ & 47,988 & 32,954 & 35,772 & 38,732 & 155,446 \\
\hline Place of care 1 & $\%^{2}$ & $\%^{2}$ & $\%^{2}$ & $\%^{2}$ & $\%^{2}$ \\
\hline Home & 89.1 & 83.0 & 92.7 & 97.8 & 90.8 \\
\hline Hospital & 66.4 & 73.5 & 63.5 & 51.2 & 63.4 \\
\hline Nursing home & 11.9 & 13.5 & 6.5 & 0.9 & 8.3 \\
\hline Hospice & 0.5 & $\mathrm{I} .4$ & 1.1 & - & 0.7 \\
\hline \multicolumn{6}{|l|}{ Places of care (in detail) } \\
\hline Only home & 26.9 & 17.0 & 32.3 & 47.9 & 31.3 \\
\hline Only nursing home & 5.5 & 7.7 & 3.9 & 0.9 & 4.5 \\
\hline Only hospital & 2.7 & 6.5 & 1.7 & 1.3 & 2.9 \\
\hline Home and hospital & 58.0 & 61.7 & 58.5 & 49.9 & 56.9 \\
\hline Nursing home and hospital & 2.7 & 1.9 & $\mathrm{I} .4$ & - & 1.6 \\
\hline Others & 4.1 & 5.2 & 2.3 & - & 2.9 \\
\hline \multirow[t]{2}{*}{ Total } & 100 & 100 & 100 & 100 & 100 \\
\hline & \multicolumn{5}{|c|}{$P<0.001$ (test for heterogeneity) } \\
\hline
\end{tabular}

I The sum is greater than 100 because a number of patients was in different places.

2 All percentages are weighted.

3 The number of cancer deaths have been estimated, using 1998 mortality data.

0.58), type of ward $(P=0.81)$, relationship $(P=0.45)$, caregiver's gender $(P=0.13)$, and age $(P=0.17)$.

Because of the negligible proportion (8.3\%) (Table 1) of patients cared for in a nursing home no analysis was carried out for this group. Overall, 12.3\% (95\% CI: 6.3 22.9) of these patients was followed by a pain specialist whilst in a nursing home.

\section{Factors associated with the referral for domiciliary PCTs} and with the involvement of a pain specialist in hospital Multivariate analyses (Table 5)

Two multivariate logistic models were fitted to the same data, using as dependent variables the referral for PCTs at home (first model) and to a pain specialist in hospital (second model).

The probability of being referred for a domiciliary PCTs significantly increased with an extended time interval from diagnosis to death $(\mathrm{P}=0.01)$ and caregivers with a higher educational level $(P=0.01)$. For caregivers other than the spouse, the probability of referral was significantly lower $(\mathrm{P}=0.03)$. Referral was less likely for patients living in the South $(\mathrm{OR}=0.13 ; 95 \% \mathrm{CI}=0.02-0.69)$, as compared to patients living in the other parts of Italy.

The probability of being followed by a pain specialist whilst in hospital significantly decreased with patient's increased age at death $(\mathrm{P}<0.01)$, and it was minimal for patients aged 85 years or more $(\mathrm{OR}=0.15 ; 95 \%$ CI 0.06 $0.41)$. This probability increased significantly with the caregiver's with a higher educational level $(P=0.01)$. The involvement of pain specialist was more likely for patients living in the North East and in the South as compared to patients living in the other geographical areas $(\mathrm{P}=0.04)$.

Table 2: validity of information regarding the referral for domiciliary PCTs reported by the caregivers.

\begin{tabular}{|c|c|c|c|c|}
\hline \multirow[b]{2}{*}{ Caregivers 1} & & \multicolumn{3}{|c|}{ Domiciliary PCTs case sheets 1} \\
\hline & & YES & NO & TOTAL \\
\hline & YES & $167(14.8)$ & $25(2.2)$ & $192(17.0)$ \\
\hline & NO & $19(1.7)$ & $918(81.3)$ & $937(83.0)$ \\
\hline & TOTAL & $186(16.5)$ & $943(83.5)$ & $1,129(100)$ \\
\hline
\end{tabular}

\footnotetext{
I For each cell number and (total percentages) are reported.

PCTs = Palliative Care Teams
} 
Table 3: determinants of referral for domiciliary PCTs by selected characteristics.

\begin{tabular}{|c|c|c|c|}
\hline & \multirow{2}{*}{$\begin{array}{c}1998 \text { Italian cancer deaths } 3 \\
\text { No. }\end{array}$} & \multicolumn{2}{|c|}{ Referred to domiciliary PCTs } \\
\hline & & $\%^{2}$ & $(95 \% \mathrm{Cl})$ \\
\hline \multicolumn{4}{|l|}{ AGE AT DEATH (years) } \\
\hline $18-54$ & 10,296 & 13.5 & $(6.7-25.4)$ \\
\hline $55-64$ & $|9,45|$ & 16.4 & $(8.8-28.6)$ \\
\hline $65-74$ & 44,336 & 14.9 & $(8.3-25.4)$ \\
\hline $75-84$ & 55,093 & 15.0 & $(8.8-24.4)$ \\
\hline \multirow[t]{2}{*}{$85+$} & 26,270 & 5.8 & $(2.6-12.6)$ \\
\hline & & \multicolumn{2}{|c|}{$P=0.01$} \\
\hline \multicolumn{4}{|l|}{ GENDER } \\
\hline Males & 89,265 & 13.9 & $(8.5-21.9)$ \\
\hline \multirow[t]{2}{*}{ Females } & 66,181 & 12.9 & $(7.2-22.2)$ \\
\hline & & \multicolumn{2}{|c|}{$P=0.66$} \\
\hline \multicolumn{4}{|l|}{ EDUCATION (years) } \\
\hline$\leq 5$ & 103,804 & 12.0 & $(7.0-19.8)$ \\
\hline $6-9$ & 26,699 & 15.8 & $(9.3-25.6)$ \\
\hline \multirow[t]{2}{*}{$10+$} & 24,628 & 17.6 & $(9.5-30.3)$ \\
\hline & & \multicolumn{2}{|c|}{$P=0.08$} \\
\hline \multicolumn{4}{|l|}{ MARITAL STATUS } \\
\hline Single 1 & 61,103 & 9.8 & $(5.4-17.1)$ \\
\hline \multirow[t]{2}{*}{ Married } & 93,220 & 16.1 & $(9.8-25.4)$ \\
\hline & & \multicolumn{2}{|c|}{$P=0.01$} \\
\hline \multicolumn{4}{|l|}{ PLACE OF RESIDENCE } \\
\hline North West & 47,988 & 18.1 & $(8.7-33.9)$ \\
\hline North East & 32,954 & 17.6 & $(7.5-36.1)$ \\
\hline Center & 35,772 & 15.6 & $(4.7-40.9)$ \\
\hline \multirow[t]{2}{*}{ South and islands } & 38,732 & 2.3 & $(0.6-8.2)$ \\
\hline & & \multicolumn{2}{|c|}{$P=0.04$} \\
\hline \multicolumn{4}{|l|}{ PRIMARY TUMOR } \\
\hline Head and neck & 3,455 & 16.6 & $(6.5-36.3)$ \\
\hline Digestive system & 56,114 & 12.4 & $(7.4-20.1)$ \\
\hline Respiratory system & 33,510 & 13.7 & $(7.1-24.9)$ \\
\hline Breast & 15,269 & 15.4 & $(7.8-28.1)$ \\
\hline Genitourinary system & 22,766 & 19.4 & $(11.5-31.0)$ \\
\hline Haematological & 11,487 & 5.9 & $(2.7-12.5)$ \\
\hline \multirow[t]{2}{*}{ Others and unspecified } & 12,845 & 10.9 & $(5.6-19.9)$ \\
\hline & & \multicolumn{2}{|c|}{$P=0.19$} \\
\hline
\end{tabular}


Table 3: determinants of referral for domiciliary PCTs by selected characteristics. (Continued)

\begin{tabular}{|c|c|c|c|}
\hline \multicolumn{4}{|c|}{ MONTHS SINCE DIAGNOSIS } \\
\hline $1-3$ & 28,657 & 9.6 & $(5.1-17.5)$ \\
\hline $4-6$ & 20,397 & 9.4 & $(4.3-19.2)$ \\
\hline $7-12$ & 27,612 & 15.1 & $(7.9-26.5)$ \\
\hline $13-36$ & $4 I, 260$ & 15.1 & $(9.1-24.1)$ \\
\hline \multirow[t]{2}{*}{$>36$} & 31,737 & 17.9 & $(10.2-29.6)$ \\
\hline & & \multicolumn{2}{|c|}{$P<0.01$} \\
\hline \multicolumn{4}{|c|}{ NUMBER OF COHABITANTS } \\
\hline None & 19,098 & 8.5 & $(3.4-19.6)$ \\
\hline 1 & 64,791 & 16.0 & $(10.2-24.0)$ \\
\hline 2 & 35,634 & 15.0 & $(7.7-26.8)$ \\
\hline \multirow[t]{2}{*}{$3+$} & 35,923 & 10.3 & $(4.7-21.2)$ \\
\hline & & \multicolumn{2}{|c|}{$P=0.69$} \\
\hline \multicolumn{4}{|c|}{ CAREGIVER (relationship) } \\
\hline Spouse - partner & $48,|8|$ & 15.9 & $(9.5-25.3)$ \\
\hline Child & 71,696 & 14.1 & $(8.3-23.0)$ \\
\hline \multirow[t]{2}{*}{ Others } & 35,568 & 9.0 & $(4.5-17.1)$ \\
\hline & & \multicolumn{2}{|c|}{$P=0.03$} \\
\hline \multicolumn{4}{|l|}{ CAREGIVER'S AGE } \\
\hline $18-44$ & 42,025 & 13.0 & $(7.3-22.1)$ \\
\hline $45-54$ & 35,486 & 13.8 & $(7.7-23.5)$ \\
\hline $55-64$ & 32,075 & 14.0 & $(7.2-25.5)$ \\
\hline $65-74$ & 26,364 & 12.6 & $(7.5-20.5)$ \\
\hline \multirow[t]{2}{*}{$75+$} & 10,245 & 11.9 & $(6.0-22.2)$ \\
\hline & & \multicolumn{2}{|c|}{$P=0.85$} \\
\hline \multicolumn{4}{|c|}{ CAREGIVER'S GENDER } \\
\hline Males & 47,477 & 11.6 & $(6.7-19.3)$ \\
\hline \multirow[t]{2}{*}{ Females } & 107,969 & 14.3 & $(8.6-22.9)$ \\
\hline & & \multicolumn{2}{|c|}{$P=0.13$} \\
\hline \multicolumn{4}{|c|}{ CAREGIVER'S EDUCATION } \\
\hline$\leq 5$ & & 10.1 & $(5.4-18.0)$ \\
\hline $6-9$ & 30,583 & 11.9 & $(6.2-21.8)$ \\
\hline \multirow[t]{2}{*}{$10+$} & 69,702 & 15.6 & $(9.8-23.9)$ \\
\hline & & \multicolumn{2}{|c|}{$P=0.02$} \\
\hline TOTAL & 155,446 & 13.5 & $(8.1-21.5)$ \\
\hline
\end{tabular}

I Including widowed, separated and divorced.

2 All percentages are weighted.

3 The number of cancer deaths have been estimated from the study sample, using 1998 Italian mortality data. 
Table 4: determinants of involvement of pain specialist in hospital by selected characteristics.

\begin{tabular}{|c|c|c|c|}
\hline & I998 Italian cancer deaths I & \multicolumn{2}{|c|}{ Followed in hospital by a specialist in pain } \\
\hline & $\mathrm{N}$ & $\%^{3}$ & $(95 \% \mathrm{Cl})$ \\
\hline \multicolumn{4}{|l|}{ AGE AT DEATH (years) } \\
\hline $18-54$ & 7,599 & 41.5 & $(24.9-60.3)$ \\
\hline $55-64$ & 14,449 & 29.2 & $(20.4-40.0)$ \\
\hline $65-74$ & 29,585 & 16.0 & $(11.5-22.0)$ \\
\hline $75-84$ & 33,982 & 17.0 & $(11.4-24.2)$ \\
\hline \multirow[t]{2}{*}{$85+$} & 12,999 & 11.4 & $(6.2-20.2)$ \\
\hline & & \multicolumn{2}{|c|}{$P<0.01$} \\
\hline \multicolumn{4}{|l|}{ GENDER } \\
\hline Males & 60,469 & 19.1 & $(13.9-25.6)$ \\
\hline \multirow[t]{2}{*}{ Females } & 38,144 & 20.5 & $(14.6-28.0)$ \\
\hline & & \multicolumn{2}{|c|}{$P=0.74$} \\
\hline \multicolumn{4}{|l|}{ EDUCATION (years) } \\
\hline$\leq 5$ & 65,804 & 16.7 & $(12.0-22.8)$ \\
\hline $6-9$ & 15,114 & 22.2 & $(15.3-30.9)$ \\
\hline \multirow[t]{2}{*}{$10+$} & 17,696 & 28.2 & $(19.5-39.0)$ \\
\hline & & \multicolumn{2}{|c|}{$P=0.01$} \\
\hline \multicolumn{4}{|l|}{ MARITAL STATUS } \\
\hline Single 2 & 34,554 & 20.0 & $(14.2-27.6)$ \\
\hline \multirow[t]{2}{*}{ Married } & 63,130 & 18.9 & $(15.0-23.6)$ \\
\hline & & \multicolumn{2}{|c|}{$P=0.72$} \\
\hline \multicolumn{4}{|l|}{ PLACE OF RESIDENCE } \\
\hline North West & 31,869 & 24.6 & $(19.8-30.1)$ \\
\hline North East & 24,208 & 13.3 & $(7.9-21.6)$ \\
\hline Center & 22,716 & 22.3 & $(13.3-25.0)$ \\
\hline \multirow[t]{2}{*}{ South and islands } & 19,821 & 16.3 & $(6.6-34.7)$ \\
\hline & & \multicolumn{2}{|c|}{$P=0.12$} \\
\hline \multicolumn{4}{|l|}{ PRIMARY TUMOR } \\
\hline Head and neck & 1,880 & 14.8 & $(5.8-32.9)$ \\
\hline Digestive system & 40,314 & 19.8 & $(14.8-25.9)$ \\
\hline Respiratory system & 22,144 & 21.9 & $(14.2-32.2)$ \\
\hline Breast & 7,205 & 13.4 & $(6.3-26.1)$ \\
\hline Genitourinary system & $|2,3| \mid$ & 23.3 & $(14.2-35.8)$ \\
\hline Haematological & 7,387 & 15.7 & $(5.9-35.7)$ \\
\hline \multirow[t]{2}{*}{ Others and unspecified } & 7,371 & 16.9 & $(9.5-28.4)$ \\
\hline & & \multicolumn{2}{|c|}{$P=0.54$} \\
\hline \multicolumn{4}{|c|}{ MONTHS SINCE DIAGNOSIS } \\
\hline $1-3$ & 25,833 & 17.4 & $(11.9-24.8)$ \\
\hline $4-6$ & $|2,04|$ & 19.2 & $(11.8-29.8)$ \\
\hline
\end{tabular}


Table 4: determinants of involvement of pain specialist in hospital by selected characteristics. (Continued)

\begin{tabular}{|c|c|c|c|}
\hline $7-12$ & 16,624 & 18.8 & $(10.9-30.4)$ \\
\hline $13-36$ & 23,213 & 19.6 & $(13.4-27.8)$ \\
\hline \multirow[t]{2}{*}{$>36$} & 18,304 & 24.8 & $(16.8-35.0)$ \\
\hline & & \multicolumn{2}{|c|}{$P=0.21$} \\
\hline \multicolumn{4}{|l|}{ ADMISSION'S WARD } \\
\hline Surgery & 20,547 & 21.1 & $(14.9-29.0)$ \\
\hline Medicine & 55,237 & 19.1 & $(14.0-25.6)$ \\
\hline Oncology-Hematology & 13,815 & 21.9 & $(13.5-33.5)$ \\
\hline \multirow[t]{2}{*}{ Other } & 9,014 & 15.6 & $(7.9-28.7)$ \\
\hline & & \multicolumn{2}{|c|}{$P=0.81$} \\
\hline \multicolumn{4}{|c|}{ NUMBER OF COHABITANTS } \\
\hline None & 7,178 & 12.8 & $(6.2-24.7)$ \\
\hline 1 & 37,988 & 18.9 & $(14.0-25.1)$ \\
\hline 2 & 22,412 & 20.9 & $(I 2.5-32.8)$ \\
\hline \multirow[t]{2}{*}{$3+$} & 20,797 & 18.5 & $(11.7-28.1)$ \\
\hline & & \multicolumn{2}{|c|}{$P=0.58$} \\
\hline \multicolumn{4}{|l|}{ CAREGIVER (relationship) } \\
\hline Spouse - partner & 28,795 & 19.3 & $(13.0-27.7)$ \\
\hline Child & 44,759 & 17.0 & $(12.5-22.8)$ \\
\hline \multirow[t]{2}{*}{ Others } & 14,820 & 23.5 & $(15.0-34.2)$ \\
\hline & & \multicolumn{2}{|c|}{$P=0.45$} \\
\hline \multicolumn{4}{|l|}{ CAREGIVER'S AGE } \\
\hline $18-44$ & 28,797 & 22.6 & $(16.9-29.4)$ \\
\hline $45-54$ & 23,331 & 20.4 & $(14.2-28.4)$ \\
\hline $55-64$ & 20,080 & 20.5 & $(|2.9-3| .0)$ \\
\hline $65-74$ & 16,040 & 13.6 & $(7.3-24.1)$ \\
\hline \multirow[t]{2}{*}{$75+$} & 6,127 & 19.2 & $(8.5-37.9)$ \\
\hline & & \multicolumn{2}{|c|}{$P=0.17$} \\
\hline \multicolumn{4}{|l|}{ CAREGIVER'S GENDER } \\
\hline Males & 26,679 & 22.8 & $(17.4-29.2)$ \\
\hline \multirow[t]{2}{*}{ Females } & 61,695 & 17.1 & $(12.5-22.9)$ \\
\hline & & \multicolumn{2}{|c|}{$P=0.13$} \\
\hline \multicolumn{4}{|l|}{ CAREGIVER'S EDUCATION } \\
\hline$\leq 5$ & 23,879 & 12.3 & $(7.9-18.4)$ \\
\hline $6-9$ & 19,490 & 16.2 & $(8.7-28.4)$ \\
\hline \multirow[t]{2}{*}{$10+$} & 41,114 & 24.5 & $(|8.5-3| .8)$ \\
\hline & & \multicolumn{2}{|c|}{$P<0.01$} \\
\hline TOTAL & 98,614 & 19.6 & $(15.5-24.5)$ \\
\hline
\end{tabular}

I Subgroup of cancer deaths who spent part of their last three months of life in hospital. The number of cancer deaths have been estimated from the study sample, using 1998 Italian mortality data.

2 Including widowed, separated and divorced.

3 All percentages are weighted. 
Table 5: Multivariate logistic regression analyses of determinants of referral.

\begin{tabular}{|c|c|c|c|c|}
\hline & \multicolumn{2}{|c|}{ Referred for domiciliary PCTs } & \multicolumn{2}{|c|}{ Referred for specialist in pain in hospital } \\
\hline & OR & $(95 \% \mathrm{Cl}){ }^{\prime}$ & OR & $(95 \% \mathrm{Cl}){ }^{\prime}$ \\
\hline \multicolumn{5}{|l|}{ The patient } \\
\hline \multicolumn{5}{|l|}{ Age at death (years) } \\
\hline $18-54$ & ref. & & ref. & \\
\hline $55-64$ & 1.04 & $(0.40-2.68)$ & 0.67 & $(0.27-1.63)$ \\
\hline $65-74$ & 0.98 & $(0.38-2.54)$ & 0.34 & $(0.14-0.83)$ \\
\hline $75-84$ & 0.98 & $(0.37-2.59)$ & 0.32 & $(0.13-0.74)$ \\
\hline \multirow[t]{2}{*}{$85+$} & 0.43 & $(0.16-1.14)$ & 0.15 & $(0.06-0.41)$ \\
\hline & & $0.10)$ & & \\
\hline \multicolumn{5}{|l|}{ Place of residence } \\
\hline North West & ref. & & ref. & \\
\hline North East & 1.08 & $(0.27-4.30)$ & 0.39 & $(0.20-0.75)$ \\
\hline Center & 0.80 & $(0.16-3.90)$ & 0.75 & $(0.35-1.61)$ \\
\hline \multirow[t]{2}{*}{ South and islands } & 0.13 & $(0.02-0.69)$ & 0.54 & $(0.20-1.44)$ \\
\hline & & $0.09)$ & & \\
\hline \multicolumn{5}{|l|}{ Months since diagnosis } \\
\hline $1-3$ & ref. & & ref. & \\
\hline $4-6$ & 0.60 & $(0.20-I .8 I)$ & 1.42 & $(0.68-3.00)$ \\
\hline $7-12$ & 1.06 & $(0.40-2.78)$ & 0.92 & $(0.40-2.10)$ \\
\hline $13-36$ & 1.44 & $(0.63-3.29)$ & 1.07 & $(0.52-2.19)$ \\
\hline \multirow[t]{2}{*}{$>36$} & 1.75 & $(0.86-3.57)$ & 1.47 & $(0.76-2.83)$ \\
\hline & & $0.01)$ & & \\
\hline \multicolumn{5}{|l|}{ The caregiver } \\
\hline \multicolumn{5}{|l|}{ Relationship } \\
\hline Spouse & ref. & & ref. & \\
\hline Child & 0.72 & $(0.5 I-I .0 I)$ & 0.85 & $(0.45-1.6 I)$ \\
\hline \multirow[t]{2}{*}{ Others } & 0.49 & $(0.28-0.85)$ & 1.20 & $(0.52-2.80)$ \\
\hline & & $0.03)$ & & \\
\hline \multicolumn{5}{|l|}{ Gender } \\
\hline Males & ref. & & ref. & \\
\hline \multirow[t]{2}{*}{ Females } & 1.40 & $(0.93-2.11)$ & 0.88 & $(0.54-1.44)$ \\
\hline & & $0.06)$ & & \\
\hline \multicolumn{5}{|l|}{ Education (years) } \\
\hline$\leq 5$ & ref. & & ref. & \\
\hline $6-9$ & 1.44 & $(0.82-2.5 \mathrm{I})$ & 1.31 & $(0.63-2.74)$ \\
\hline \multirow[t]{2}{*}{$10+$} & 2.00 & $(1.20-3.35)$ & 2.36 & $(1.25-4.46)$ \\
\hline & & $0.01)$ & & \\
\hline
\end{tabular}

I OR $(95 \% \mathrm{Cl})$ estimated by multivariate logistic regression with all patient's and caregiver's covariates included in the model. Only covariates with a P-value $<0.10$ for at least one of the two models are reported.

Table 6: domiciliary PCTs and hospices in Italy in the 30 LHDs sampled in ISDOC study.

\begin{tabular}{|c|c|c|c|c|c|c|c|c|c|c|}
\hline & \multicolumn{5}{|c|}{ 2002-2003 (ISDOC) } & \multicolumn{5}{|c|}{ at June 2006} \\
\hline & $\begin{array}{c}\text { Italy } \\
(n=30)\end{array}$ & $\begin{array}{c}N W \\
(n=9)\end{array}$ & $\begin{array}{c}N E \\
(n=6)\end{array}$ & $\begin{array}{l}\text { Center } \\
(n=7)\end{array}$ & $\begin{array}{l}\text { South } \\
(n=8)\end{array}$ & $\begin{array}{c}\text { Italy } \\
(\mathrm{n}=30)\end{array}$ & $\begin{array}{c}N W \\
(n=9)\end{array}$ & $\begin{array}{c}N E \\
(n=6)\end{array}$ & $\begin{array}{l}\text { Center } \\
(n=7)\end{array}$ & $\begin{array}{l}\text { South } \\
(\mathrm{n}=8)\end{array}$ \\
\hline \multicolumn{11}{|l|}{ DOMICILIARY PCTs } \\
\hline Total number & 23 & 13 & 4 & 4 & 2 & 24 & 13 & 4 & 4 & 3 \\
\hline LHD with I or more PCTs & 16 & 8 & 3 & 3 & 2 & 17 & 8 & 3 & 3 & 3 \\
\hline \multicolumn{11}{|l|}{ INPATIENT HOSPICE } \\
\hline Total number & 3 & 1 & 1 & 1 & - & 12 & 6 & 4 & 2 & - \\
\hline Total beds & 24 & 10 & 6 & 8 & - & 128 & 79 & 31 & 18 & - \\
\hline LHD with I or more hospice & 3 & 1 & I & 1 & - & 7 & 3 & 3 & 1 & - \\
\hline
\end{tabular}

PCTs = Palliative Care Teams

LHD= Local Health District 


\section{Trend in domiciliary PCTs and hospices availability (Table 6)}

Table 6 shows the trends of the development of domiciliary PCTs and hospices in the 30 sampled LHD in the last 4 years. The number of domiciliary PCTs remained almost the same in all geographical areas during this time window. Overall, the number of hospices increased 4 fold (from 3 to 12) and the total beds available 5 times (from 24 to 128 ). The observed increase was confined mainly to the Northern and Central regions, while no increase was observed in the South of the country.

\section{Discussion}

This is the first population-based survey performed at a national level exploring the places of care, the provision of and the access to palliative care services of Italian cancer patients in their last three months of life. The validity and generalizability of these results must be interpreted taking into account strengths and limitations of the study design [21]. Although the post-bereavement surveys overcome problems related with prospective studies impaired by the practical difficulties of obtaining representative cohorts of terminal cancer patients [24], evaluating to what extent the information regarding the access and utilization of palliative care services is valid and accurate may be problematic. In this survey, only information on the domiciliary referral of patients for PCTs (and the date of their first visit) was obtained from the original case sheets. Conversely, information on the palliative care support received in hospital, as socio demographic and clinical characteristics of the patients and their caregiver, was collected through interviews with the bereaved non-professional caregivers.

A review of studies that compares patients' and proxies' view [25] suggests that proxies can reliably report on the quality of services and objective symptoms. For pain, anxiety and depression, that are more subjective aspects of the patient's experience, the agreement is poorest. Our findings are supported by the validity of the information reported by the caregivers regarding patients' referral to domiciliary PCTs. These results emphasize the appropriateness of the post-bereavement surveys as a methodology to gather valid data on practical aspects of the patient's experience, and support the use of the caregivers as a source of valid information [25].

The distribution of care settings throughout country was polarised into two main places: home and hospital where most cancer patients spend the entire or part of their last three months of life. Significant geographical differences were observed in the combination of these places of care. Similar differences were observed as regards the place of death of cancer patients in Italy [26] and within Italian regions [27]. The observed broad differences in place of death and of care across the country, suggest an inappropriate use of hospital resources during the terminal phase of disease.

A very low proportion of Italian cancer patients received palliative care support: $14 \%$ of those cared for at home and $20 \%$ of those admitted to hospital.

Population-based palliative care studies recently carried out in different countries, showed a coverage proportion ranging between $19 \%$ and $68 \%[9,10,12,28,29]$.

Italian cancer patients received palliative care at home, with clear geographical differences reflecting an unequal provision of and access to palliative care services across the country. Only a few districts in the South of Italy offer PCTs with limited access. Conversely, the similar proportion of patients receiving palliative care in the other regions of the country, is the product of an unequal combination of different provision of services (higher in the North West) and of referrals to the existing services (higher in the North East and in the Centre). The analysis of the trend over time in terms of provision of services shows an unchanged availability of domiciliary PCTs and a significant increase in the provision of hospices. Unfortunately, this change, limited to the North and, to a lesser extent, to the Centre of Italy, worsens the overall situation in terms of equity. The increased availability of hospices is largely due to the policy of the Ministry of Health, strongly supporting and funding this type of service [30], rather than funding a global palliative care program. Moreover, in the absence of any national instrument to promote, support, and assess the development of the program, and with a federal government of the Health Service, the more developed regions of the North of Italy are more likely to make use of national funds to create or expand palliative care services. As a consequence, inequities are expected to become even more marked in the near future.

Geographic variation in the availability and provision of palliative care programs, is present in others countries where there has been a rapid and unplanned development of services and programs [4-6,28].

For Italian cancer patients admitted to hospital, no significant difference was found between the four geographical areas and the admission wards. An Italian survey carried out in 40 hospitals aimed at evaluating how people die in hospital general wards, showed that acute inpatient institutions in Italy are inadequate to cope with the needs of dying patients [19]. Independently from the geographical areas, hospital PCTs in Italian hospitals are lacking, and even pain counselling from $\mathrm{a}$ is available for only a minority of patients. 
According with the literature [4,7], Italian cancer patients cared for at home and referred for domiciliary PCTs, differ significantly from not referred patients for a number of factors. The multivariate logistic regression showed that the most important determinants of referral are the time window from diagnosis to death and the caregivers' educational level. Generally, the conditions of short-term survivors can rapidly alter, and the dying trajectory unpredictable [12]. For this group of patients it is more difficult to establish links with community support, to plan and organize the referral for domiciliary PCTs $[7,8,13]$. The caregiver's educational level, often an index of their socio-economic status, affects the skill and ability to identify and obtain the more appropriate healthcare services $[7,31]$.

The multivariate logistic regression analysis also revealed that the Italian cancer patients who are elderly and supported by a caregiver with a low educational level are less likely to be referred to a pain specialist whilst in hospital. A number of reasons for non referral of older people to palliative care have been reported in medical literature suggesting that older patients might experience less pain, less-severe symptoms and less psychological distress than younger patients $[4,7,11,12]$. This may be reflected in an obsolete view of some physicians involved in cancer care and research, who do not consider adapting care to the needs of patients of different age groups [9]. Moreover, there is evidence that pain is underreported and under treated among elderly cancer patients [32]. The considerations reported for palliative home care services regarding the educational level of the caregiver, can be also be applied in this context.

\section{Conclusion}

The results of this survey show that both the provision of palliative care services and the access to existing services, are inadequate in quantity and, more important, unequally distributed across Italy. Moreover, the analysis of determinants of referral identifies the level of education of both the patients and the caregivers as an important factor of access to the health services. It is important to note that inequity in provision and access puts patients and families who are already socially disadvantaged at a further disadvantage with respect to their health [33]. This may result from a spontaneous and unregulated development of palliative care services without any national program for the assessment of the quality of care provided. In the absence of a specific plan targeted at reducing inequalities, the simple allocation of funds for the development of new palliative care services might even worsen the situation. As from 2006 palliative care for cancer patients must be provided by the National Health System, and health policymakers should invest in funding effective, palliative care services and networks both at home and in hospital. A monitoring system aimed at identifying inequities both in provision and in access is needed to ensure equitable access to palliative care for all members of society.

\section{Competing interests}

The author(s) declare that they have no competing interests.

\section{Authors' contributions}

$\mathrm{MC}$ is the principal investigator of the survey and guarantor. $\mathrm{MC}$ and $\mathrm{MB}$ designed the survey and the research materials. All the members of the ISDOC study group (Appendix 1) discussed and approved the final protocol of the survey. $\mathrm{MC}$ and $\mathrm{MB}$ coordinated the survey at a national level. $\mathrm{MB}, \mathrm{MC}$ and DFM analysed the data, interpreted and discussed the results presented in this article. This paper was primarily written by $\mathrm{MB}$ and $\mathrm{MC}$, and then revised, discussed and emended by all the authors that approved the final version of the manuscript.

\section{Appendix I}

\section{The ISDOC study group}

Massimo Costantini, Monica Beccaro, Maria Pia Sormani, Paolo Bruzzi (Unit of Clinical Epidemiology, National Cancer Institute, Genova); Domenico Franco Merlo (Unit of Epidemiology and Biostatistics, National Cancer Institute, Genoa); Gabriella Morasso, Silvia Di Leo (Psychology Service, National Cancer Institute, Genoa); Paolo Giorgi Rossi, Piero Borgia (Agency for Public Health, Lazio Region, Rome); Maurizio Montella, Maria Grimaldi (Department of Epidemiology, National Cancer Institute, G.Pascale Foundation, Naples); Eugenio Paci, Nicoletta Susini, Riccardo Cecioni, Guido Miccinesi (Clinical Epidemiology, Centre for the Study and Prevention of Cancer, Florence); Renato Pisanti (Labos Foundation, Rome).

\section{Acknowledgements}

This work was supported by the grant from the Italian Minister of Health (Progetto di Ricerca Finalizzata 200 I-2003). The authors thanks Jacqueline Luzardo for data entry and S. Bennett (Fondazione Maruzza Lefebvre D'Ovidio - Onlus, Rome) for English revision of the manuscript.

\section{References}

I. Higginson I: Palliative and terminal care. In Health care needs assessment. 2nd series Edited by: Andrew Stevens, James Raffery. Oxford: Radcliffe Medical Press; 1997:183-260.

2. Seale C: Changing patterns of death and dying. Soc Sci Med 2000, 51 : $917-930$.

3. Clark D, Centeno C: Palliative Care in Europe: an emerging approach to comparative analysis. Clin Med 2006, 6(2):197-20I.

4. Ahmed N, Bestall JC, Ahmedzai SH, Payne SA, Clark D, Noble B: Systematic review of the problems and issues of accessing specialist palliative care by patients, carers and health and social care professionals. Palliat Med 2004, I 8(6):525-42.

5. Wood DJ, Clark D, Gatrell AC: Equity of access to adult hospice inpatients care within north-west England. Palliat Med 2004, I 8(6):543-9. 
6. Roscoe LA, Schonwetter RS: Improving access to hospice and palliative care for patients near the end of life: present status and future direction. J Palliat Care 2006, 22(I):46-50.

7. Grande GE, Addington-Hall JM, Todd CJ: Place of death and access to home care services: are certain patient groups at a disadvantage? Soc Sci Med 1998, 47(5):565-579.

8. Costantini M, Camoirano E, Madeddu L, Bruzzi P, Verganelli E, Henriquet $F$ : Palliative home care and place of death among cancer patients: a population-based study. Palliat Med 1993 7(4):323-33I.

9. Addington-Hall J, Altmann D: Which terminally cancer patients in the United Kingdom receive care from community specialist palliative care nurses? J Adv Nurs 2000, 32(4):799-806.

10. Burge F, Johnston G, Lawson B, Dewar R, Cummings I: Populationbased trends in referral of the elderly to a comprehensive palliative care programme. Palliat Med 2002, I6(3):255-6.

1I. Grande GE, Mc Kerral A, Todd C): Which patients are referred to Hospital at Home for palliative care? Palliat Med 2002 16:115-123.

12. Hunt RW, Fazekas BS, Luke CG, Priest KR, Roder DM: The coverage of cancer patients by designated palliative services: a population-based study, South Australia, 1999. Palliat Med 2002, 16:403-409.

13. Tang ST: Determinants of hospice home care use among terminally ill cancer patients. Nurs Res 2003, 52(4):2 I7-25.

14. Tyrer F, Exley C: Receiving care at home at end of life: characteristics of patients receiving hospice at home care. Family Practice 2005, 22:644-646.

15. Bruera E, Neumann M, Gagnon B, Brenneis C, Kneisler P, Selmser P, Hanson J: Edmonton Regional Palliative Care Program: impact on patterns of terminal cancer care. CMAJ 1999 , I61(3):290-3.

16. Middlewood S, Gardner G, Gardner A: Dying in Hospital: Medical Failure or Natural Outcome? J Pain Symptom Manage 200I, 22(6): $|035-4|$.

17. Finlay IG, Higginson IJ, Goodwin DM, Cook AM, Edwards AGK, Hood K, Douglas HR, Normand CE: Palliative care in hospital, hospice, at home: results from a systematic review. Ann Oncol 2002, 13(4):257-64.

18. Ellershaw J, Ward C: Care of the dying patient: the last hours or days of life. BMJ 2003, 326(7379):30-4.

19. Toscani F, Di Giulio P, Brunelli C, Miccinesi G, Laquintana D: How people die in hospital general wards: A descriptive study. J Pain Symptom Manage 2005, 30(I):33-40.

20. Pantilat SZ, Billings JA: Prevalence and structure of palliative care services in California Hospitals. Arch Intern Med 2003, 163:1084-1088.

21. Costantini M, Beccaro M, Merlo F: The last three months of life of Italian cancer patients. methods, sample characteristics and response rate of the Italian survey of the dying of cancer (ISDOC). Palliat Med 2005, 19:628-638.

22. Addington-Hall J, Walker L, Jones C, Karlsen S, McCarthy M: A randomised controlled trial of postal versus interviewer administration of a questionnaire measuring satisfaction with, and use of, services received in the year before death. J Epidemiol Community Health 1998, 52:802-807.

23. Società Italiana di Cure Palliative [http://www.sicp.it/centri.asp]

24. Earle CC, Ayanian JZ: Looking back from death: the value of retrospective studies of end-of-life care. J Clin Oncol 2006, 24(6):838-40.

25. McPherson CJ, Addington-Hall JM: Judging the quality of care at the end of life: can proxies provide reliable information? Soc Sci Med 2003, 56:95-109.

26. Beccaro M, Costantini M, Giorgi Rossi P, Miccinesi G, Grimaldi M, Bruzzi P: Actual and preferred place of death of cancer patients. Results from the Italian Survey of the Dying Of Cancer (ISDOC). I Epidemiol Community Health 2006, 60:4I2-4I6.

27. Costantini M, Balzi D, Garrone E, Orlandini C, Parodi S, Vercelli M, Bruzzi P: Geographical variations of place of death among Italian communities suggest an inappropriate hospital use in the terminal phase of cancer disease. Public Health 2000, I I 4: 15-20.

28. Centeno C, Hernansanz S, Flores LA, Rubiales AS, Lòpez-Lara F: Spain: Palliative Care Programs in Spain, 2000: a national survey. J Pain Symptom Manage 2002, 24(2):245-5I.
29. Rosenwax LK, McNamara BA: Who receives specialist palliative care in Western Australia - and who misses out. Palliat Med 2006, 20:439-445.

30. Ministero della Salute. Approfondimenti: Strutture residenziali di cure palliative (2006) [http://www.ministerosalute.it/ investimenti/]

31. Giorgi Rossi P, Beccaro M, Miccinesi G, Borgia P, Costantini M, Chin F, Baiocchi D, De Giacomi G, Grimaldi M, Montella M, ISDOC Study Group: Dying of cancer in Italy: impact on family and caregiver. The ISDOC survey. J Epidemiol Community Health 2007, 60:546-53.

32. Bernabei R, Gambassi G, Lapane K, Landi F, Gatsonis C, Dunlop R, Dunlop R, Lipsitz L, Steel K, Mor V: Management of pain in elderly cancer patients. JAMA 1998, 279: $1877-1882$.

33. Braveman P, Gruskin S: Defining equity in health. J Epidemiol Community Health 2003, 57:254-258.

\section{Pre-publication history}

The pre-publication history for this paper can be accessed here:

http://www.biomedcentral.com/1471-2458/7/66/prepub
Publish with Biomed Central and every scientist can read your work free of charge

"BioMed Central will be the most significant development for disseminating the results of biomedical research in our lifetime. "

Sir Paul Nurse, Cancer Research UK

Your research papers will be:

- available free of charge to the entire biomedical community

- peer reviewed and published immediately upon acceptance

- cited in PubMed and archived on PubMed Central

- yours - you keep the copyright
BioMedcentral 